\section{RSP}

http://www.rsp.fsp.usp.br/
Revista de Saúde Pública

\title{
Effects of a strategy for the promotion of physical activity in students from Bogotá
}

\author{
Leidys Gutiérrez-Martínez',"I, Rocío Gámez Martínez"I", Silvia A González',IV, Manuel A Bolívarv \\ Omaira Valencia Estupiñan', Olga L Sarmiento'
}

Universidad de los Andes. Facultad de Medicina. Grupo de Epidemiología. Bogotá, Colombia

" Fundación Valle del Lili. Centro de Investigaciones Clínicas. Cali, Colombia

III Instituto Distrital de Recreación y Deporte. Bogotá, Colombia

Iv Children's Hospital of Eastern Ontario Research Institute. Healthy Active Living and Obesity Research Group. Ontario, Canada

$\checkmark$ Universidad de los Andes. Facultad de Ingeniería. Centro para la Optimización y la Probabilidad Aplicada. Bogotá, Colombia

\section{ABSTRACT}

OBJECTIVE: To examine the effect of the promotion of physical activity during recess on the levels of physical activity, sedentary behaviors, and adiposity of Colombian students.

METHODS: Three schools were randomly selected by an intervention group in Bogotá, Colombia, in 2013: Intervention (Active Module of Active Recess - MARA) + Text Messages (SMS) (MARA+SMS group), intervention (MARA group), control (control group). Intervention was implemented for ten weeks. The duration and intensity of physical activity and sedentary behaviors were measured objectively using accelerometers Actigraph-GT3X+. Adiposity was measured by body mass index and fat percentage. We measured at baseline (T0) and during the tenth week of intervention (T1). We evaluated the effect of the intervention using a difference-in-difference analysis (DID).

RESULTS: We included 120 students ( $57.5 \%$ girls; mean age $=10.5$ years; standard deviation $[\mathrm{SD}]=0.64)$. There was a significant increase in the mean daily minutes of moderate to vigorous physical activity in the MARA group (Difference T1-T0 = 6.1 minutes, standard error [SE $]=3.49$, $\mathrm{p}=0.005$ ) in relation to the control group. There were no significant changes in the minutes of moderate to vigorous physical activity in the MARA+SMS group (Difference T1-T0 = -1.0 minute; $\mathrm{SE}=3.06 ; \mathrm{p}=0.363$ ). The minutes decreased in the control group (Difference T1-T0 = -7.7 minutes; $\mathrm{SE}=3.15 ; \mathrm{p}=0.011$ ). The minutes of sedentary behaviors decreased in the MARA and MARA+SMS groups and increased in the control group (MARA Difference T1-T0 = -15.8 minutes; $\mathrm{SE}=10.05$; $\mathrm{p}=0.279 ; \mathrm{MARA}+\mathrm{SMS}$ Difference T1-T0 = -11.5 minutes; $\mathrm{SE}=8.80 ; \mathrm{p}=0.869$; Control Difference T1-T0 = 10.9 minutes; SE = 9.07; $\mathrm{p}=0.407$ ). There was a higher participation in the MARA group in relation to the MARA+SMS group (MARA group = 34.4\%; MARA+SMS group = $12.1 \%$ ). There were no significant changes in adiposity at 10 weeks according to difference-in-differences analysis (body mass index p: $\triangle \mathrm{MARA}+\mathrm{SMS}$ group versus $\Delta$ control group $=0.945, \Delta$ MARA group versus $\Delta$ control group $=0.847, \Delta$ MARA + SMS group versus $\triangle$ MARA group $=0.990 ;$ FP p $\triangle M A R A+S M S$ group versus $\Delta$ control group $=0.788, \Delta$ MARA group versus $\Delta$ control group $=0.915, \Delta \mathrm{MARA}+\mathrm{SMS}$ group versus $\triangle$ MARA group $=0.975$ ).

CONCLUSIONS: The Active Module of Active Recess is a promising strategy to increase physical activity levels and decrease sedentary behavior in students. The addition of Text Messages was not associated with increased moderate to vigorous physical activity or changes in adiposity.

DESCRIPTORS: School Health. Exercise. Mobile Applications, utilization. Body Mass Index. Sedentary Lifestyle. Health Behavior. Health Promotion. 


\section{INTRODUCTION}

Childhood overweight and obesity are a global public health problem ${ }^{1}$ and at least $10 \%$ of the children in the world are overweight or obese $e^{2}$. Between 22.5 and 25.9 million children suffer from overweight or obesity in Latin America ${ }^{3}$, and this number reaches one in six children and adolescents aged between five and seventeen years in Colombia ${ }^{4}$. The promotion of physical activity (PA) and the decrease of the time dedicated to sedentary behaviors (SB) are fundamental in preventing childhood obesity ${ }^{5,6}$. However, $74 \%$ of the population aged between 13 and 17 years do not follow the recommendations of PA and $57.9 \%$ of the children aged between five and 12 years dedicate two hours per day or more to SB in Colombia ${ }^{4,7,8}$.

Physical education classes and recess time are fundamental for the promotion of PA in students, since children and adolescents spend between six and eight hours a day in school' Consequently, strategies involving recess time are promising interventions for the promotion of PA in students ${ }^{10-13}$.

The incorporation of information technologies has shown the potential to promote healthy lifestyles and health-related structural changes, such as text messages (SMS) that encourage healthy behaviors through immediate feedback and advice ${ }^{14,15}$.

Policies exist to extend the student journey in Colombia, strengthening areas such as mathematics, natural sciences, and English, but they do not include PA or sports activities ${ }^{16}$. However, Bogota was a model for the promotion of PA in students through district programs aimed at the school community ${ }^{17}$. Successful local experiences of community programs in urban settings have been described ${ }^{18,19}$, but studies on the impact of interventions together with SMS to promote PA and decrease SB in student settings are limited. Therefore, the objective of this study was to examine the effect of a intervention for the promotion of PA during recess, intensified by a SMS strategy, on the levels of PA, SB, and adiposity in students from Bogotá.

\section{METHODS}

This is a randomized community trial carried out with fifth grade students from three schools located in San Cristóbal in Bogotá, DC, Colombia, between July and November 2013.

The included schools were selected from the 20 eligible schools of the International Study of Childhood Obesity, Lifestyles, and the Environment (ISCOLE) ${ }^{20}$. We performed a previous random sampling with the dimensions of socioeconomic level $(1,2$, and 3$)$, number of students $(1,200-3,400)$, level of self-reported PA in a previous study ( $4.9 \%-11.8 \%$ of compliance with the recommendations of moderate to vigorous physical activity [MVPA]), and distance from the school to the Ciclovia $(<1 \mathrm{~km})$. The Ciclovia is a program which temporarily closes the streets to all motorized transport allowing only the access to persons for recreational activities ${ }^{21}$. The number of included schools was determined by the availability of resources for the new implementation of the Active Module of Active Recess (MARA) by the District Institute of Recreation and Sport (IDRD).

The intervention was part of the multi-component program named Movam Se Estudantes of the IDRD of Bogotá. This strategy seeks to promote PA in students by integrating elements, structured activities, and supervision. The activities were designed to improve cardiovascular capacity, speed, muscle strength, coordination, and teamwork skills ${ }^{21}$.

The MARA module transformed the usual recess space with standardized activities lasting 20 minutes from the 30 minutes of the usual recess time, three times a week for 10 weeks. The MARA module included 30 PA sessions that combined games with elements such as bows, balls, hoops, ladders, parachutes, tablecloths, rumba, and gaming sessions. In case of

${ }^{a}$ For the material with the programmed activities, please contact the corresponding author. unforeseen circumstances to carry out the programmed activity, an alternative was used. All sessions were directed and supervised by the PA managers of the IDRD ${ }^{\mathrm{a}}$. 
The MARA+SMS group received a daily SMS to promote the participation of the students in the intervention and its dissemination among partners, to motivate the performance of the PA in the context outside school and with the family, and to encourage a healthy diet. The SMS written by expert psychologists were sent to the cell phones of parents and some students, according to the approval of parents and the instruction of the Ethics Committee of the Universidade dos Andes. Parents were asked to show their children every SMS received, if the participant did not receive it directly.

The three selected schools were randomly chosen for an intervention or control group: intervention at recess time (MARA) together with SMS (MARA+SMS group), intervention only (MARA group), and control group (control group) (Figure 1) without any intervention. Data were collected in two periods: before the beginning of the intervention (T0) and during the tenth week of intervention (T1). There was no risk of contamination for the control group as the school was located more than $1 \mathrm{~km}$ from the intervention schools, and the implementation of the strategy depended on IDRD personnel.

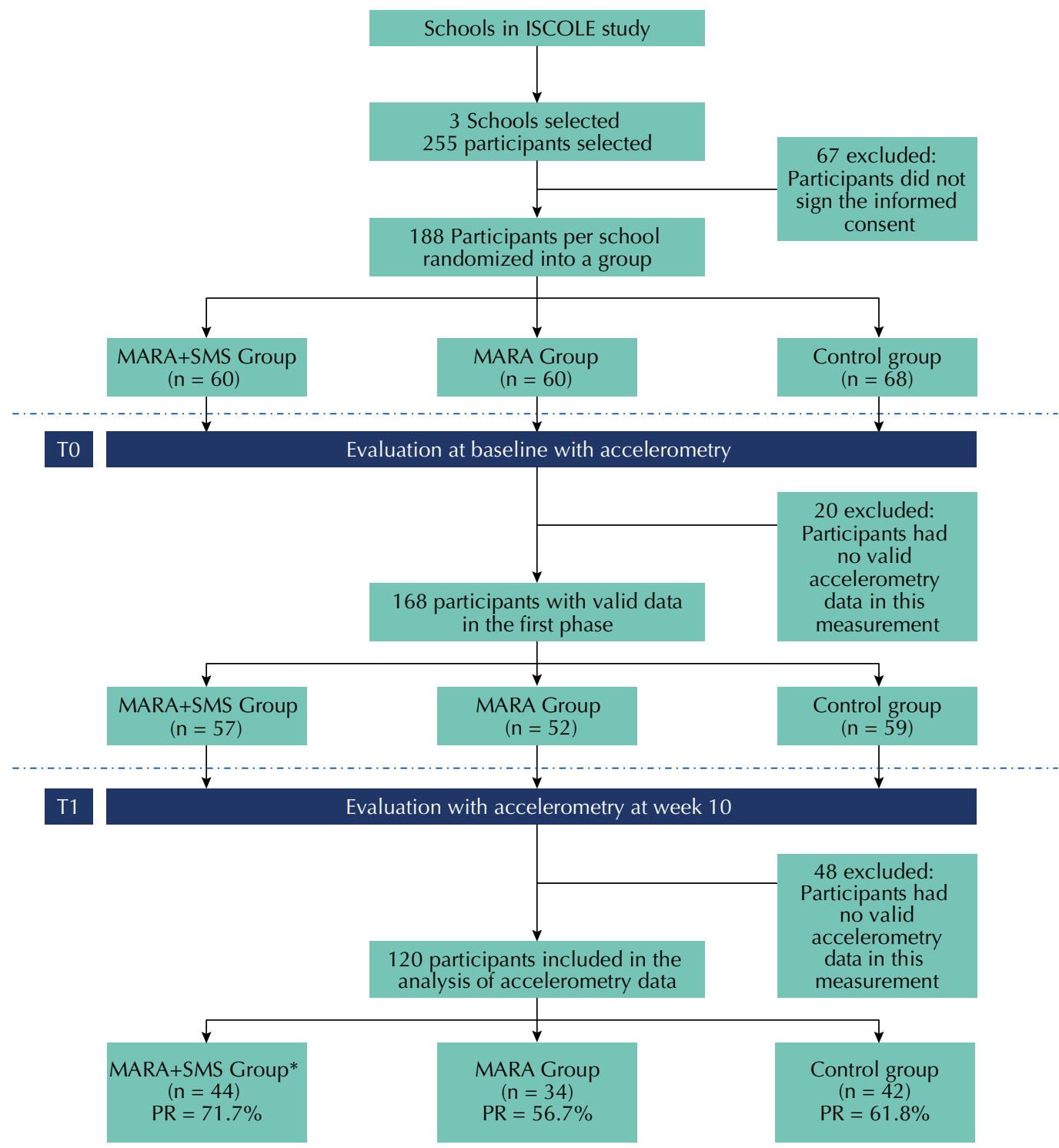

ISCOLE: International Study of Childhood Obesity, Lifestyles, and the Environment; MARA+SMS group: Intervention of Active Module of Active Recess + Text Messages; MARA group: Intervention of Active Module of Active Recess; BMI: body mass index; T0: baseline at time zero; T1: follow-up period at week 10 of intervention; PR: percentage of response

* One participant in this group dropped out before week 10. However, it was included in the final analysis with the intention-to-treat analysis.

Figure 1. Flowchart of the sampling. 
The levels of PA and SB were objectively measured using accelerometers Actigraph GT3X+ (ActiGraph, Pensacola, FL). The accelerometer was used in an elastic belt over the right midaxillary line. Students were instructed to use the accelerometer 24 hours a day for at least seven days, after one day of familiarization, including two weekend days. The minimum acceptable amount of valid accelerometry data included three weekdays, with at least 10 hours of daily use. In the work days, we did not take into account weekend days, since the evaluated intervention was performed on weekdays. The data were compiled with a sampling frequency of $80 \mathrm{~Hz}$, downloaded in one-second epochs and grouped in 15-second epochs for analysis ${ }^{22}$. After data collection, we validated the time of use with software R3.2.3. According to Evenson cut-off points, we defined MVPA as $\geq 574$ counts per 15 seconds and physical inactivity as $\leq 25$ counts per 15 -second epochs ${ }^{23}$. We encouraged the daily use of the accelerometer with decals that the students put on these devices or their journals.

We performed the following anthropometric measurements: size, weight, fat percentage (FP), abdominal perimeter, and the middle third of the arm. Participant size was measured using the portable stadiometer Seca 230 (Hamburg, Germany), using the Frankfort plan. Weight and FP, calculated by bipolar electrical bioimpedance (EBI), were measured using the Portable Body Composition Analyzer Tanita SC-240 (Arlington Heights, IL). Each measurement was taken twice and the mean was used for the analyses. Body mass index (BMI) was calculated using the formula weight $(\mathrm{kg}) / \mathrm{height}^{2}\left(\mathrm{~m}^{2}\right)$. We determined the nutritional status of the children according to BMI using the z-scores derived from the standard deviation (SD) of the measurement, established in the growth patterns of the World Health Organization $(\mathrm{WHO})^{24}$; we grouped risk of thinness and thinness.

The sociodemographic variables included were: sex, age, socioeconomic level, education level, and marital status of the parents. In Bogotá, socioeconomic level is classified from one (low-low) to six (high) according to the characteristics of the households, being 1-2-3 the lowest levels ${ }^{25}$. This information was reported by parents using the sociodemographic and family information questionnaire. Age was calculated with the date of birth and the date of the anthropometric measurements. We evaluated behaviors related to PA, physical inactivity, and eating habits using the diet and lifestyle questionnaire designed for the ISCOLE study and adapted for this study ${ }^{20}$. This questionnaire was administered by a researcher to each participant during intervention days. Some questions related to daily PA and physical inactivity were adapted from the American Youth Risk Behavior Surveillance System $\left(\right.$ YRBSS $^{26}$. We designed a component to question the time and type of activities during recess and a satisfaction module about MARA.

Statistical analysis was performed in four phases. First, we carried out a univariate analysis to describe the sociodemographic characteristics, type and frequency of the activities during recess, consumption of food, and anthropometric characteristics. Daily and weekday $\mathrm{PA}$ and SB were evaluated as a continuous variable, in mean minutes, with previous log transformation, since the data did not present a normal distribution. Second, we evaluated heterogeneity between groups (MARA+SMS group versus MARA group versus control group) using Fisher homogeneity test for categorical variables and ANOVA for continuous variables. Third, we performed a bivariate and multivariate analysis with intention-to-treat analysis for students with valid accelerometry data using mixed multilevel models - individual and school - adjusted for sex and age. We evaluated the effect of the intervention using a difference-in-differences analysis (DID) of absolute values, with the models proposed in the previous step, to compare the changes in the levels of $\mathrm{PA}, \mathrm{SB}$, and adiposity over time (T0 versus $\mathrm{T} 1$ ) among the three study groups. All possible combinations were considered: MARA+SMS group versus control group, MARA group versus control group, MARA+SMS group versus MARA group.

We compared the intensity of some types of activities implemented in MARA by plotting the mean counts per minute of the assistants of a session of each activity in one of the schools involved, using software R3.2.3. Statistical analysis was performed in SAS 9.3 and Stata 13. Data on the continuous PA variables were expressed as means. 
The strategy implementation processes were evaluated with eleven semi-structured interviews with the teachers of the participating schools and members of the IDRD team. These interviews were recorded in audio and transcribed verbatim. We took notes when the interviewee did not agree to be recorded. We reviewed the project documents, including protocol, meeting minutes, field work formats, service lists, and SMS. We qualitatively evaluated the process, context, and conditions of the research implementation in these documents. In addition, we analyzed the service lists to understand the dynamics of student participation in the proposed activities.

We sent informed consents to the schools and parents or guardians of potential participants to authorize their inclusion in the study. Similarly, students signed an informed consent accepting their participation. The study was approved by the ethics committee of the Universidade dos Andes (Process 214-2013).

\section{RESULTS}

The total sample consisted of 184 students, and $45.7 \%$ complied with the recommendations of PA, according to the mean dailyMVPA obtained with accelerometry(MARA+SMS group $=43.9 \%$; MARA group $=31.7 \%$; control group $=59.7 \%$; $\mathrm{p}=0.844$ )

There were no significant differences between groups, except for socioeconomic level. The MARA+SMS group had a higher percentage of boys living in level 3 households (Table 1).

The data analysis of the reported AP, accelerometry, and adiposity was performed with 120 students, $36.7 \%$ of the MARA+SMS group, $28.3 \%$ of the MARA group, and $35.0 \%$ of the control group. The control group reported a higher percentage of behaviors associated with PA in relation to the MARA+SMS and MARA groups during most of the recess $(p=0.039)($ Table 2).

The prevalence of overweight was $19.3 \%$ in the MARA+SMS group, $23.3 \%$ in the MARA group, and $16.4 \%$ in the control group ( $\mathrm{p}=0.867)$. The FP was in an optimal range for most students (MARA+SMS group 75.4\%; MARA group 76.7\%; control group 64.2\%; $\mathrm{p}=0.111$ ). There were no statistically significant differences between the groups for the indicators of adiposity evaluated neither for the daily consumption of fruits and vegetables or high-calorie food reported (Table 1).

Between baseline and week 10, daily minutes of MVPA were kept in the MARA+SMS group $(p=0.702)$, increased 6.1 (standard error $[\mathrm{SE}]=3.49)$ minutes in the MARA group $(\mathrm{p}=0.044)$, and decreased $7.7(\mathrm{SE}=3.15)$ minutes in the control group $(\mathrm{p}=0.005)$ (DID $\triangle \mathrm{MARA}+\mathrm{SMS}$ group versus $\Delta$ control group; $\mathrm{p}=0.005$ ) (DID $\Delta$ MARA group versus $\Delta$ control group; $\mathrm{p}=0.005$ ). This trend was kept in the mean minutes of MVPA on weekdays.

The daily minutes of SB decreased 11.5 (SE = 8.8) minutes in the MARA+SMS group ( $\mathrm{p}=0.869)$ and 15.8 (SE = 10.05) minutes in the MARA group ( $\mathrm{p}=0.279)$, and it increased 10.9 (SE = 9.07) minutes in the control group ( $\mathrm{p}=0.407$ ) (DID $\triangle \mathrm{MARA}+\mathrm{SMS}$ group versus $\Delta$ control group; $\mathrm{p}=0.003$ ) (DID $\triangle$ MARA group versus $\Delta$ control group; $\mathrm{p}=0.003$ ). This trend was kept in the mean minutes of SB on weekdays.

No significant effect was observed on BMI or FP in any of the three groups evaluated (DID BMI p $\triangle$ MARA+SMS group versus $\Delta$ control group $=0.945, \triangle$ MARA group versus $\Delta$ control group $=0.847$; DID FP p $\triangle$ MARA+SMS group versus $\Delta$ control group $=0.788, \Delta$ MARA group versus $\Delta$ control group $=0.915)$ between baseline and week 10 (Table 3$)$.

Parachute activity reached the highest levels of PA compared to other activities (Figure 2).

Preference was reported for activities that included games with balls (37.1\%), games with parachute (21.4\%), and rumba (15.7\%). Additionally, $47.2 \%$ identified MARA as an opportunity to do PA during recess and $94.4 \%$ reported interest in keeping doing it. 
Table 1. Characteristics of students from Bogotá by intervention group at baseline in 2013.

\begin{tabular}{|c|c|c|c|c|c|c|c|}
\hline \multirow[t]{2}{*}{ Variable } & \multicolumn{2}{|c|}{$\frac{\text { MARA+SMS group }}{(n=57)}$} & \multicolumn{2}{|c|}{$\begin{array}{c}\text { MARA group } \\
(n=60)\end{array}$} & \multicolumn{2}{|c|}{$\begin{array}{c}\text { Control group } \\
(n=67)\end{array}$} & \multirow[t]{2}{*}{$\mathbf{p}$} \\
\hline & $\mathbf{n}$ & $\%$ & $\mathbf{n}$ & $\%$ & $\mathbf{n}$ & $\%$ & \\
\hline \multicolumn{8}{|c|}{ Sociodemographic } \\
\hline \multicolumn{8}{|l|}{ Sex } \\
\hline Male & 24 & 42.1 & 24 & 40.0 & 31 & 46.3 & 0.789 \\
\hline Female & 33 & 57.9 & 36 & 60.0 & 36 & 53.7 & \\
\hline Mean age in years and SDa & 10.4 & 0.7 & 10.4 & 0.6 & 10.6 & 0.8 & 0.125 \\
\hline \multicolumn{8}{|l|}{ Socioeconomic level ${ }^{b}$} \\
\hline 1 and 2 & 37 & 64.9 & 58 & 96.7 & 63 & 94.0 & $<0.001$ \\
\hline 3 & 20 & 35.1 & 2 & 3.3 & 4 & 6.0 & \\
\hline \multicolumn{8}{|l|}{ Education level of the parents ${ }^{c}$} \\
\hline Bellow high school - high school & 43 & 75.4 & 46 & 76.7 & 57 & 85.1 & 0.346 \\
\hline $\begin{array}{l}\text { Licentiate/Vocational school/ } \\
\text { Undergaduate/Graduate }\end{array}$ & 14 & 24.6 & 14 & 23.3 & 10 & 14.9 & \\
\hline \multicolumn{8}{|l|}{ Marital status of the parents } \\
\hline Married & 8 & 14.0 & 16 & 26.7 & 18 & 26.9 & 0.160 \\
\hline Divorced/Separated/Widowed & 20 & 35.1 & 12 & 20.0 & 21 & 31.3 & \\
\hline Never married & 29 & 50.9 & 32 & 53.3 & 28 & 41.8 & \\
\hline \multicolumn{8}{|c|}{ Anthropometric } \\
\hline \multicolumn{8}{|l|}{ BMI z-score for age ${ }^{d}$} \\
\hline Thin & 1 & 1.8 & 1 & 1.7 & 2 & 3.0 & 0.867 \\
\hline Appropriate for age & 45 & 78.9 & 45 & 75.0 & 54 & 80.6 & \\
\hline Overweight/Obesity & 11 & 19.3 & 14 & 23.3 & 11 & 16.4 & \\
\hline \multicolumn{8}{|l|}{ Fat percentage } \\
\hline Low & 6 & 10.5 & 5 & 8.3 & 15 & 22.4 & 0.111 \\
\hline Normal & 43 & 75.5 & 46 & 76.7 & 43 & 64.2 & \\
\hline Overweight & 4 & 7.0 & 4 & 6.7 & 8 & 11.9 & \\
\hline Obesity & 4 & 7.0 & 5 & 8.3 & 1 & 1.5 & \\
\hline \multicolumn{8}{|l|}{ Daily consumption of high-calorie foods } \\
\hline No consumption & 46 & 80.7 & 46 & 76.7 & 53 & 79.1 & 0.876 \\
\hline Daily consumption & 11 & 19.3 & 14 & 23.3 & 14 & 20.9 & \\
\hline \multicolumn{8}{|c|}{ Daily consumption of fruits and vegetables } \\
\hline No consumption & 25 & 43.9 & 34 & 56.7 & 31 & 46.3 & 0.335 \\
\hline Daily consumption & 32 & 56.1 & 26 & 43.3 & 36 & 53.7 & \\
\hline Mean minutes of daily MVPA ${ }^{e}$ & 61.9 & 3.1 & 56.6 & 3.5 & 67.7 & 3.1 & 0.141 \\
\hline
\end{tabular}

MARA+SMS Group: intervention of Active Module of Active Recess + text messages; MARA Group: intervention of Active Module of Active Recess; BMI: body mass index

a SD: standard deviation of age in years.

b Socioeconomic level goes from 1 (low-low) to 6 (high) according to the characteristics of the households, and

1-2-3 are the lowest levels.

c The sum of the observations is not equal to total $n$ because of missing values.

d The categories were defined according to the z-scores established in the growth patterns of the World Health Organization (WHO): $z<-2$ SD thinness; -2 SD $<z<-1$ DE risk of thinness; -1 SD $<z<1$ SD appropriate for age; 1 SD $<z<2$ SD overweight; $z>2$ SD obesity.

e MVPA: moderate to vigorous physical activity. These results were obtained by accelerometry with $n=120$.

The environmental, safety, and time factors were the main reasons for no participation in MARA. Approximately $40.0 \%$ of the students reported not doing any PA because of an environmental factor ( $26.6 \%$ because of the cold; $12.5 \%$ because of the heat). Approximately $10.0 \%$ thought it was dangerous to play at recess. Approximately $10.0 \%$ of the children reported that recess time and facilities were not enough.

The physical environment, characteristics of the student (ages, preferences, course composition), and type of activity were identified as relevant factors that affected MARA acceptance and participation. The most successful activities identified by the teachers and members of the IDRD were those involving the following elements: parachutes, bows or balls, those related to skills, running, with a lot of movement, and rumba.

Another important factor associated with the implementation and acceptability of the intervention was the work of PA managers in the follow-up of the intervention. Specifically, 
Table 2. Descriptive statistics of the frequency of self-reported activities during recess at baseline and week 10. Bogotá, Colombia, 2013.

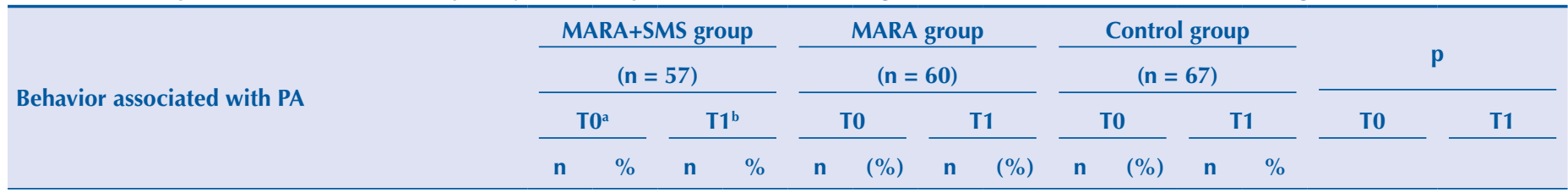

Frequency of PA during recess in the last 7 days ${ }^{c}$

$\begin{array}{lccccccccccccccc}\text { Always } & 18 & 31.6 & 18 & 31.6 & 23 & 38.3 & 32 & 53.3 & 27 & 40.3 & 16 & 23.9 & 0.737 & 0.01 \\ \text { Sometimes } & 35 & 61.4 & 36 & 63.2 & 31 & 51.7 & 26 & 43.3 & 33 & 49.3 & 47 & 70.2 & & & \\ \text { Never } & 4 & 7.0 & 3 & 5.3 & 6 & 10.0 & 2 & 3.3 & 7 & 10.5 & 4 & 6.0 & & & \end{array}$

Most frequent activities during recess in the last 7 days ${ }^{\mathrm{d}}$

Sedentary behaviors

Behavior associated with light $\mathrm{PA}^{\mathrm{f}}$

Behavior associated with moderate to vigorous $\mathrm{PA}^{\mathrm{g}}$ $\begin{array}{llll}9 & 15.8 \quad 2 \quad 3\end{array}$

$3 \quad 5.3 \quad 3 \quad 5.3$

$45 \quad 79.0 \quad 52$

$\begin{array}{ccccccccc}3.5 & 3 & 5.0 & 5 & 8.3 & 6 & 9.0 & 6 & 9.0 \\ 5.3 & 11 & 18.3 & 6 & 10.0 & 14 & 20.9 & 8 & 11.9 \\ 1.2 & 46 & 76.7 & 49 & 81.7 & 47 & 70.2 & 53 & 79.1\end{array}$

MARA+SMS Group: intervention of Active Module of Active Recess + text messages; MARA Group: intervention of Active Module of Active Recess;

BMI: body mass index; PA: physical activity

a T0: baseline.

b T1: week 10 .

${ }^{c}$ Original question of the questionnaire: How often did you practice a PA during recess in the last seven days?

${ }^{\mathrm{d}}$ Original question of the questionnaire: In the last seven days, which of the following activities were more often during recess?

e This category includes the following activities: eating, sitting (talking, reading, doing school work).

${ }^{f}$ This category includes the following activities: standing or walking.

${ }^{g}$ This category includes the following activities: running and playing a little, running and playing some time, running and playing most of the time.

Table 3. Effect of the intervention on the mean minutes of physical activity, physical inactivity, and indicators of adiposity of students from Bogotá by intervention group in 2013.

\begin{tabular}{|c|c|c|c|c|c|c|c|c|c|}
\hline \multirow{3}{*}{ Variable } & \multirow{2}{*}{\multicolumn{2}{|c|}{$\begin{array}{c}\text { MARA+SMS group } \\
(n=44)\end{array}$}} & \multirow{2}{*}{\multicolumn{2}{|c|}{$\begin{array}{l}\text { MARA group } \\
\qquad(n=34)\end{array}$}} & \multirow{2}{*}{\multicolumn{2}{|c|}{$\begin{array}{l}\text { Control group } \\
\qquad(n=42)\end{array}$}} & \multicolumn{3}{|c|}{$\begin{array}{l}\text { P-values of difference-in-differences } \\
\text { analysis } \\
\end{array}$} \\
\hline & & & & & & & \multirow{2}{*}{$\begin{array}{l}\text { MARA } \\
\text { versus } \\
\text { Control }\end{array}$} & \multirow{2}{*}{$\begin{array}{l}\text { MARA+SMS } \\
\text { versus } \\
\text { Control }\end{array}$} & \multirow{2}{*}{$\begin{array}{l}\text { MARA+SMS } \\
\text { versus } \\
\text { MARA }\end{array}$} \\
\hline & $\mathrm{TO}^{\mathrm{a}}$ & $\mathrm{T} 1^{\mathrm{b}}$ & Tо & T1 & то & T1 & & & \\
\hline Daily MVPA (SE) & $61.9(3.06)$ & $60.9(3.06)$ & $56.6(3.49)$ & $62.7(3.49)$ & $67.7(3.15)$ & $60.0(3.15)$ & 0.005 & 0.005 & 0.005 \\
\hline MVPA on weekdays (SE) & $65.8(3.27)$ & $64.4(3.27)$ & $60.2(3.73)$ & $63.9(3.73)$ & $72.5(3.36)$ & $63.3(3.36)$ & 0.005 & 0.005 & 0.005 \\
\hline Daily light PA (SE) & $311.9(7.33)$ & $294.8(7.33)$ & $279.3(8.36)$ & $298.0(8.36)$ & $301.2(7.54)$ & $281.3(7.54)$ & 0.002 & 0.003 & 0.002 \\
\hline Light PA on weekdays (SE) & $318.7(7.48)$ & $301.1(7.48)$ & $281.6(8.54)$ & $305.1(8.54)$ & $308.9(7.70)$ & $283.2(7.70)$ & 0.002 & 0.003 & 0.002 \\
\hline Daily physical inactivity (SE) & $543.6(8.80)$ & $532.1(8.80)$ & $547.6(10.05)$ & $531.8(10.05)$ & $502.5(9.07)$ & $513.3(9.07)$ & 0.003 & 0.003 & 0.001 \\
\hline Physical inactivity on weekdays (SE) & $566.3(9.62)$ & $548.2(9.62)$ & $561.9(10.99)$ & $539.9(10.99)$ & $504.3(9.92)$ & $523.6(9.92)$ & 0.003 & 0.004 & 0.001 \\
\hline BMI z-score (SE) & $0.05(0.16)$ & $0.1(0.16)$ & $0.4(0.19)$ & $0.4(0.19)$ & $-0.2(0.17)$ & $-0.1(0.17)$ & 0.847 & 0.945 & 0.990 \\
\hline Fat percentage (SE) & $18.9(0.82)$ & $20.0(0.83)$ & $20.2(1.03)$ & $21.1(1.03)$ & $18.1(0.93)$ & $18.8(0.93)$ & 0.915 & 0.788 & 0.975 \\
\hline
\end{tabular}

MVPA: moderate to vigorous physical activity; SE: standard error; PA: physical activity; BMI: body mass index

a T0: baseline.

b $\mathrm{T} 1$ : week 10 .

The values of physical activity are the mean minutes.

the constant presence of a team of managers created a safe environment for students, which allowed them to identify with MARA and keep their participation over time. However, the presence of younger students in the MARA was identified as a factor so that the target age group of MARA did not get involved.

Teachers reported that the SMS strategy worked to reinforce the self-esteem of students by their recognition from someone perceived as an external authority figure (the research group). Barriers were identified that might mitigate the effect of the SMS, including difficulties in receiving SMS, lack of interest in MARA or SMS, and perception of an inadequate physical environment. 


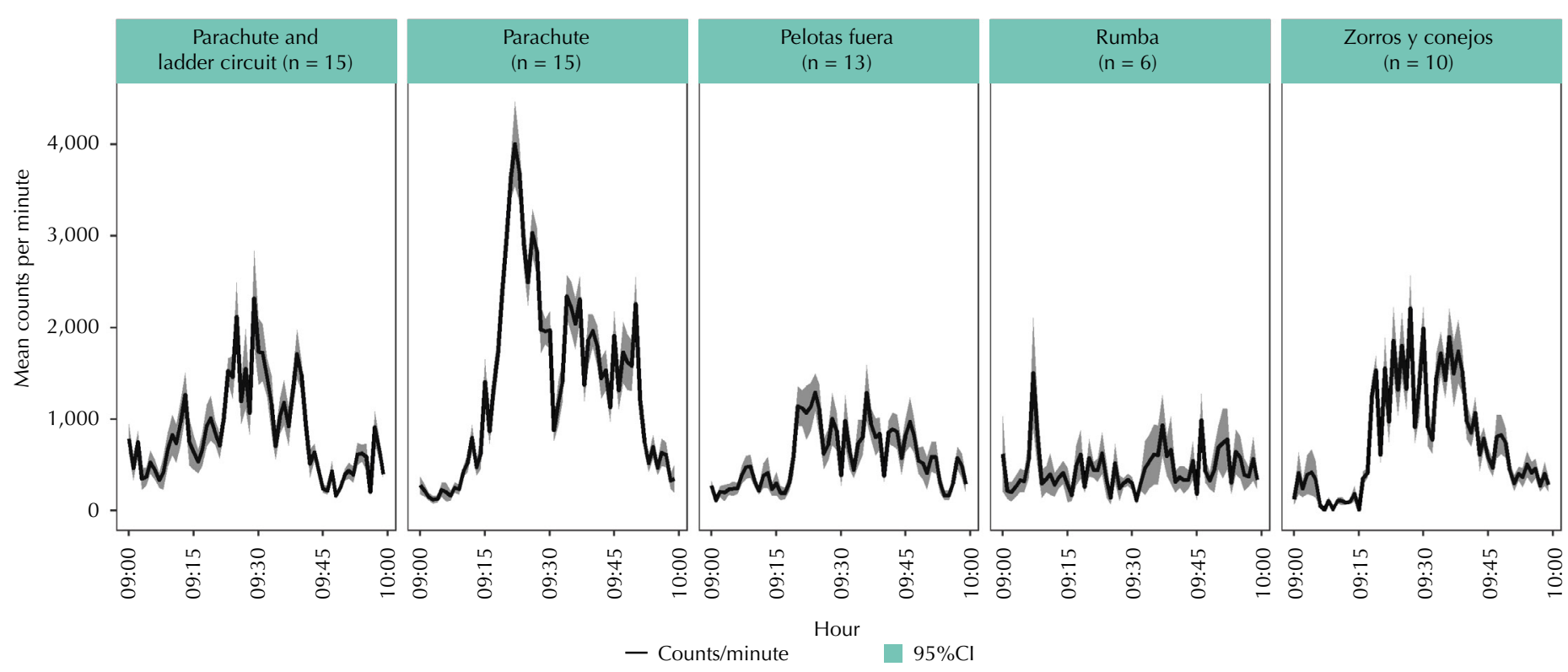

* This time of the student's day includes the 30 minutes of recess in which each activity indicated in the upper part of the Figure was implemented.

Figure 2. Intensity of the physical activity in the mean counts per minute with 95\% confidence interval, measured in one hour of the student's day* in the participating schools.

\section{DISCUSSION}

The main finding of this study is the potential of MARA to increase the minutes of daily MVPA and decrease the minutes of SB in students. The increase of 6.1 minutes in daily MVPA reported in the MARA group represents $10.1 \%$ of the recommended daily time for this age group, together with a decrease between 11.5 and 15.8 minutes in SB in the groups with intervention. These results contrast with the decrease in the minutes of MVPA and the increase of SB in the control group. Regardless of the group, there was no effect on the indicators of adiposity.

Our results are consistent with those reported in previous studies on interventions during recess ${ }^{12,13}$. Howe et al. ${ }^{12}$ have shown that the participation of students in an intervention with structured recess could contribute with an increase of $8 \pm 1.1$ minutes of MVPA, that is, an increase from $6.9(\mathrm{SD}=0.8)$ to $14.9(\mathrm{SD}=0.9)$ minutes in a 30-minute recess. Ridgers et al. ${ }^{27}$ have found that an intervention with redesign of play spaces during recess resulted in an increase of $4.5 \%$ in MVPA and 2.3\% in vigorous PA during recess. In addition, a systematic review has included nine controlled trials that have evaluated interventions to promote $\mathrm{PA}$ during recess. This study has reported an increase in MVPA (between $4.0 \%$ and $12.9 \%$ ) when they were implemented with play elements and marking of areas ${ }^{28}$.

On the other hand, the lack of effect on the indicators of adiposity is debatable in light of the available evidence. The lack of consensus was attributed to the high heterogeneity of duration, intensity, and type of PA of the interventions ${ }^{29}$. A meta-analysis has included 18 studies with interventions in primary school students involving a central component of PA and lasting between 12 and 72 months. This study has exposed the potential of these interventions for a healthy BMI despite the high heterogeneity among the included studies ${ }^{30}$. Therefore, it is possible that the duration of MARA has not been enough to achieve changes in the indicators of adiposity.

The participation of children in PA was associated with entertainment and being appropriate for age ${ }^{31}$. In this study, we obtained a percentage of participation of $34.4 \%$ in the MARA group compared to $12.1 \%$ in the MARA+SMS group. This suggests an association between participation and increased minutes of PA. According to the satisfaction survey and the process analysis, the perception of disagreement between the age of the students 
and the proposed activities, as well as the physical environment, negatively affected the participation in MARA. The MARA group had a better physical environment in terms of size and accessibility compared to the MARA+SMS group. This difference could affect the participation in each group, since the students in schools with better physical surroundings got involved up to 20 minutes more in MVPA per week ${ }^{32,33}$.

The SMS communication strategy was not associated with an increase in the minutes of PA or changes in the indicators of adiposity. In this sense, the success of this strategy is in its ability to reach an emotional level in the person, in addition to communicating a risk ${ }^{14}$. In this study, although $97.7 \%$ of the students reported receiving the SMS, they operated in a social context where the decision to participate in MARA was affected by other factors, among them, interest in the activities offered.

This study presented limitations. Only three schools were evaluated, given the limited resources for the new implementation of MARA by the IDRD. Future studies should consider a larger sample. The estimated difference in minutes of PA over the 10 weeks included all students with valid accelerometry data. However, the highest percentage of students participating in MARA with accelerometer was $47.0 \%$. Consequently, the sample evaluated with accelerometry includes students who probably did not participate in the proposed activities. For this reason, the increase in daily minutes of MVPA could not be attributed solely to MARA. However, we can suggested that it has the potential to make students aware of the practice of PA in other settings and times of the day.

The number of MARA sessions was fulfilled according to the methodology exposed, despite the interruptions in its implementation because of the temporary work stoppage in the schools. During the year, there were protests for better working conditions for teachers in the public sector, which led to the interruption of the classes for several days.

The MARA transformed the recess space, adapting to the available infrastructure and incorporating elements of the Colombian culture. However, the interpretation of these results should be made considering the context of a pilot study. Therefore, the number of schools evaluated and the intervention time limit the generalization of the results. Future interventions should consider a previous study of the profile of the students so that the activities offered better fit their interests and implementation should last at least six months. The redesign of the intervention should consider the inclusion of teachers or students in social service of each institution trained by the IDRD.

This is the first time that an objective evaluation of this type of intervention has been carried out in a randomized community trial in Bogotá with the local sports and recreation agency (IDRD). This alliance enabled these results and lessons learned to transcend from the inquiring scope to the practice. The intervention was incorporated with the support of policies in each school and a 40-week PA pedagogical plan was designed in some schools in Bogotá.

In Latin America, student interventions focused on physical education classes were identified as the only community intervention to promote PA with solid evidence for the development of recommendations $\mathrm{s}^{34}$. This study provides evidence on the effectiveness of MARA to increase PA and decrease daily physical inactivity during recess in the context of a vulnerable sector of the Colombian capital. These findings indicate the potential to escalate a similar intervention to other middle-income countries. In addition, these results could be the focus of a national public policy to protect the active recess of students as a unique opportunity, free of barriers to accessibility, to engage them in more active lifestyles.

\section{REFERENCES}

1. Karnik S, Kanekar A. Childhood obesity: a global public health crisis. Int J Prev Med. 2012 [cited 2015 Jan 1];3(1):1-7. Available from: https://www.ncbi.nlm.nih.gov/pmc/articles/PMC3278864/ 
2. Lobstein T, Baur L, Uauy R. Obesity in children and young people : a crisis in public health. Obes Rev. 2004;5 Suppl 1:4-85. https://doi.org/10.1111/j.1467-789X.2004.00133.x

3. Rivera JA, Cossío TG, Pedraza LS, Aburto TC, Sánchez TG, Martorell R. Childhood and adolescent overweight and obesity in Latin America: a systematic review. Lancet Diabetes Endocrinol. 2014;2(4):321-32. https://doi.org/10.1016/S2213-8587(13)70173-6

4. Instituto Colombiano de Bienestar Familiar. Encuesta Nacional de la Situación Nutricional en Colombia - ENSIN, 2010. Bogotá (DC): ICBF; 2010.

5. Dugan SA. Exercise for preventing childhood obesity. Phys Med Rehabil Clin N Am. 2008;19(2):205-16. https://doi.org/10.1016/j.pmr.2007.11.001

6. Loprinzi PD, Cardinal BJ, Loprinzi KL, Lee H. Benefits and environmental determinants of physical activity in children and adolescents. Obes Facts. 2012;5(4):597-610. https://doi.org/10.1159/000342684

7. Organización Mundial de la Salud. Recomendaciones mundiales sobre actividad física para la salud. Ginebra: OMS; 2015 [cited 2015 Jan 1]. Available from: http://www.who.int/ dietphysicalactivity/factsheet_recommendations/es/

8. Instituto Colombiano de Bienestar Familiar. Encuesta Nacional de Situación Nutricional en Colombia 2005. Bogotá (DC): ICBF; 2005 [cited 2015 Jan 1]. Available from: https://www. minsalud.gov.co/sites/rid/Lists/BibliotecaDigital/RIDE/VS/ED/GCFI/Ensin 2005.pdf

9. Wechsler H, Devereaux RS, Davis M, Collins J. Using the school environment to promote physical activity and healthy eating. Prev Med. 2000;31(2):S121-37. https://doi.org/10.1006/pmed.2000.0649

10. Hatfield DP, Chomitz VR. Increasing children's physical activity during the school day. Curr Obes Rep. 2015;4(2):147-56. https://doi.org/10.1007/s13679-015-0159-6

11. Viciana J, Mayorga-Vega D, Martínez-Baena A. Moderate-to-vigorous physical activity levels in physical education, school recess, and after-school time: influence of gender, age, and weight status. J Phys Act Health. 2016;13(10):1117-23. https://doi.org/10.1123/jpah.2015-0537

12. Howe CA, Freedson PS, Alhassan S, Feldman HA, Osganian SK. A recess intervention to promote moderate-to-vigorous physical activity. Pediatr Obes. 2012;7(1):82-8. https://doi.org/10.1111/j.2047-6310.2011.00007.x

13. Scruggs PW, Beveridge SK, Watson DL. Increasing children's school time physical activity using structured fitness breaks. Pediatr Exerc Sci. 2003;15(2):156-69. https://doi.org/10.1123/pes.15.2.156

14. Neuhauser L, Kreps GL. eHealth communication and behavior change: promise and performance. Soc Semiot. 2010;20(1):9-27. https://doi.org/10.1080/10350330903438386

15. Sharifi M, Dryden EM, Horan CM, Price S, Marshall R, Hacker K, et al. Leveraging text messaging and mobile technology to support pediatric obesity-related behavior change: a qualitative study using parent focus groups and interviews. J Med Internet Res. 2013;15(12):e272. https://doi.org/10.2196/jmir.2780

16. Ministerio de Educación Nacional (CO). Resolución número 4210 de 12 de septiembre de 1996. Bogotá (DC); 1996 [cited 2012 Sep 1]. Available from: http://www.mineducacion.gov. co/1759/articles-96032_archivo_pdf.pdf

17. González SA, Castiblanco MA, Arias-Gómez LF, Martinez-Ospina A, Cohen DD, Holguin GA, et al. Results from Colombia's 2016 Report Card on Physical Activity for Children. J Phys Act Health. 2016;13(11 Suppl 2):S129-36. https://doi.org/10.1123/jpah.2016-0369

18. Torres A, Díaz MP, Hayat MJ, Lyn R, Pratt M, Salvo D, et al. Assessing the effect of physical activity classes in public spaces on leisure-time physical activity: "Al Ritmo de las Comunidades": a natural experiment in Bogotá, Colombia. Prev Med. 2016;103 Suppl: S51-58. https://doi.org/10.1016/j.ypmed.2016.11.005

19. Torres A, Sarmiento OL, Stauber C, Zarama R. The Ciclovia and Cicloruta programs: promising interventions to promote physical activity and social capital in Bogotá, Colombia. Am J Public Health. 2013;103(2):e23-30. https://doi.org/0.2105/AJPH.2012.301142

20. Katzmarzyk PT, Barreira TV, Broyles ST, Champagne CM, Chaput JP, Fogelholm M, et al. The International Study of Childhood Obesity, Lifestyle and the Environment (ISCOLE): design and methods. BMC Public Health. 2013;13:900. https://doi.org/10.1186/1471-2458-13-900

21. Alcaldía Mayor de Bogotá, Instituto Distrital de Recreación y Deporte. Muévete Escolar: "un presente activo, por un futuro saludable". Bogotá (DC): IDRD; 2017 [cited 2018 Feb]. Available from: http://www.idrd.gov.co/sitio/idrd/node/496 
22. Barreira TV, Schuna JM, Tudor-Locke C, Chaput JP, Church TS, Fogelholm M, et al. Reliability of accelerometer-determined physical activity and sedentary behavior in school-aged children: a 12-country study. Int J Obes Suppl. 2015;5 Suppl 2:S29-35. https://doi.org/ 10.1038/ijosup.2015.16

23. Evenson KR, Catellier DJ, Gill K, Ondrak KS, McMurray RG. Calibration of two objective measures of physical activity for children. J Sports Sci. 2008;26(14):1557-65. https://doi.org/10.1080/02640410802334196

24. WHO Multicentre Growth Reference Study Group. WHO Child Growth Standards based on length/height, weight and age. Acta Paediatrica. 2006;95(S450):76-85. https://doi.org/10.1111/j.1651-2227.2006.tb02378.x

25. Departamento Administrativo Nacional de Estadística (CO). Estratificación socioeconómica para servicios públicos domiciliarios. Bogotá (DC): DANE; 2015 [cited 2012 Sep 1]. Available from: http://www.dane.gov.co/index.php/servicios-al-ciudadano/servicios-de-informacion/ estratificacion-socioeconomica\#generalidades

26. Centesr for Disese Control and Prevention. Youth Risk Behavior Surveillance System (YRBSS). Atlanta: CDC; 2012 [cited 2012 Sep 1]. Available from: http://www.cdc.gov/healthyyouth/data/yrbs/index.htm

27. Ridgers ND, Stratton G, Fairclough SJ, Twisk JWR. Long-term effects of a playground markings and physical structures on children's recess physical activity levels. Prev Med. 2007;44(5):393-7. https://doi.org/10.1016/j.ypmed.2007.01.009

28. Parrish AM, Okely AD, Stanley RM, Ridgers ND. The effect of school recess interventions on physical activity: a systematic review. Sports Med. 2013;43(4):287-99. https://doi.org/10. 007/s40279-013-0024-2

29. Guerra PH, Nobre MRC, Silveira JAC, Taddei JAAC. The effect of school-based physical activity interventions on body mass index: a meta-analysis of randomized trials. Clinics (Sao Paulo). 2013;68(9):1263-73. https://doi.org/10.6061/clinics/2013(09)14

30. Mei H, Xiong Y, Xie S, Guo S, Li Y, Guo B, et al. The impact of long-term schoolbased physical activity interventions on body mass index of primary school children: a meta-analysis of randomized controlled trials. BMC Public Health. 2016;16:205. https://doi.org/10.1186/s12889-016-2829-z

31. Landry BW, Driscoll SW. Physical activity in children and adolescents. PMR. 2012;4(11):826-32. https://doi.org/10.1016/j.pmrj.2012.09.585

32. Button B, Trites S, Janssen I. Relations between the school physical environment and school social capital with student physical activity levels. BMC Public Health. 2013;13:1191. https://doi.org/10.1186/1471-2458-13-1191

33. Knuth AG, Hallal PC. School environment and physical activity in children and adolescents: sytematic review. Braz J Phys Act Health. 2012;17(6):463-73. https://doi.org/10.12820/RBAFS.V.17N6P463-473

34. Ribeiro IC, Parra DC, Hoehner CM, Soares J, Torres A, Pratt M, et al. School-based physical education programs: evidence-based physical activity interventions for youth in Latin America. Glob Health Promot. 2010;17(2):5-15. https://doi.org/10.1177/1757975910365231

Funding: Order 569-2012 of the Administrative Department of Science, Technology, and Innovation (Colciencias - Contract 750-2013). Gutiérrez-Martínez L was supported as a Young Researcher of Colciencias, Order 761-2016. Inter-university order (2013) and Order to finish projects of the vice-rectory of research of Universidade dos Andes (2016). District Institute of Recreation and Sport (IDRD).

Authors' Contribution: RG, SAG, OLS participated in the design and project of the study. LG, RG, SAG, MB, OV, OLS participated in the analysis and interpretation of data. All authors contributed in the elaboration of the study, its critical revision, approval of the final version, and assume its responsibility.

Conflict of Interest: The authors declare no conflict of interest. 